\title{
OPEN The incidence and clinical features of PEGylated filgrastim-induced acute aortitis in patients with breast cancer
}

\author{
Sang Yoon Lee ${ }^{1}$, Eun Kyoung Kim ${ }^{1 凶}$, Ji-Yeon Kim² ${ }^{2}$ Taek-kyu Park ${ }^{1}$, Seung-Hyuk Choi ${ }^{1}$, \\ Young-Hyuck $\mathrm{Im}^{2}$, Min Yeong Kim ${ }^{3}$, Yeon Hee Park ${ }^{2}$ \& Duk-Kyung Kim ${ }^{1}$
}

\begin{abstract}
Although PEGylated filgrastim-induced aortitis is very rare and unknown clinically, some cases were reported and increasing, especially in breast cancer patients. The present study investigated the prevalence, clinical features and treatment of aortitis induced by PEGylated filgrastim in patients with breast cancer. A total of 2068 consecutive patients who underwent neoadjuvant/adjuvant chemotherapy with PEGylated filgrastim for breast cancer were enrolled. From the medical record, clinical, laboratory, medication, and imaging evaluation findings were collected. PEGylated filgrastiminduced aortitis was established in $0.3 \%$ of the study population. Common clinical presentations included extremely high fever and chest/back pain with high levels of inflammatory markers without any signs of infection. Contrast-enhanced computed tomography scans revealed typical enhancing wall thickening and periaortic soft tissue infiltration at various levels of aorta. All patients improved rapidly after treatment with modest doses of prednisolone $(0.5 \mathrm{mg} / \mathrm{kg} / \mathrm{day})$ without any complications. Clinicians should be aware of aortitis as a possible complication of granulocyte-colony stimulating factor therapy, especially PEGylated filgrastim, given the frequent misdiagnoses in neutropenic patients undergoing chemotherapy.
\end{abstract}

Aortitis is a rare clinical manifestation caused by multiple etiologies including infection or autoimmune disease $\mathrm{e}^{1,2}$. While several drugs such as ergot alkaloids, dopaminergic drugs or methysergide have been known to be the primary cause of chronic aortitis, drugs that cause acute aortitis are very rarely reported ${ }^{2}$. Recombinant human granulocyte-colony stimulating factors (G-CSF) are widely used for primary or secondary prevention of chemotherapy-induced neutropenia in patients treated with anticancer agents. The use of G-CSF is generally considered safe with relatively mild side effects such as bone pain ${ }^{3}$. However, critical cardiovascular adverse events including arterial thrombosis or aortitis are rarely reported ${ }^{4-6}$.

In clinical field, there are several kinds of G-CSF agents. Filgrastim and lenograstim, which is a short-acting agent of G-CSF, have very similar biological structure and activity compared to endogenous human G-CSF; PEGylated filgrastim is a long-acting agent of G-CSF ${ }^{7}$. According to cases reported to date, several types of G-CSF (filgrastim, lenograstim, lipegfilgrastim and PEGylated filgrastim) can cause aortitis in patients with various types of malignancies ${ }^{6,8-20}$. The exact incidence of G-CSF related aortitis is unknown; however, it was more frequently detected in patients with breast cancer, ovarian cancer or lymphoma ${ }^{20}$. In particular, PEGylated filgrastim, usually used for primary prophylaxis of neutropenia in breast cancer patients, is known to be associated with the highest incidence of aortitis among G-CSF agents.

Despite the small but increasing number of cases reported for the past 10 years, the incidence, clinical characteristics and management of G-CSF-related aortitis are still unclear. In the absence of large-scale data other than those derived from case reports or adverse drug reports, we sought to investigate the prevalence, clinical features and treatment of G-CSF-induced acute aortitis in patients treated with adjuvant or neoadjuvant chemotherapy and PEGylated filgrastim for breast cancer.

\footnotetext{
${ }^{1}$ Division of Cardiology, Department of Medicine, Heart Vascular Stroke Institute, Samsung Medical Center, Sungkyunkwan University School of Medicine, \#81 Irwon-ro, Gangnam-gu, Seoul 06351, Republic of Korea. ${ }^{2}$ Division of Hematology-Oncology, Department of Medicine, Samsung Medical Center, Sungkyunkwan University School of Medicine, Seoul, Republic of Korea. ${ }^{3}$ Department of Radiology, Samsung Medical Center, Sungkyunkwan University School of Medicine, Seoul, Republic of Korea. ${ }^{\varpi}$ email: ekbobi.kim@samsung.com
} 


\begin{tabular}{|c|c|}
\hline & $\begin{array}{l}\text { Breast cancer patients with PEGylated filgrastim } \\
(n=2068)\end{array}$ \\
\hline Age, years & $49.9 \pm 11.1$ \\
\hline \multicolumn{2}{|l|}{ Sex } \\
\hline Female & $2065(99.9 \%)$ \\
\hline Male & $3(0.1 \%)$ \\
\hline \multicolumn{2}{|l|}{ Chemotherapy indication } \\
\hline Neoadjuvant & $995(48.1 \%)$ \\
\hline Adjuvant & $1073(51.9 \%)$ \\
\hline \multicolumn{2}{|l|}{ Chemotherapy regimen } \\
\hline Doxorubicin + cyclophosphamide & $243(11.8 \%)$ \\
\hline Docetaxel + cyclophosphamide & $383(18.5 \%)$ \\
\hline Docetaxel + doxorubicin + cyclophosphamide & $724(35.0 \%)$ \\
\hline Docetaxel + carboplatin & $369(17.8 \%)$ \\
\hline Others & $349(16.9 \%)$ \\
\hline \multicolumn{2}{|l|}{ G-CSF with chemotherapy } \\
\hline PEGylated filgrastim & $2068(100 \%)$ \\
\hline Pegfilgrastim & $1438(69.5 \%)$ \\
\hline Tripegfilgrastim & $567(27.4 \%)$ \\
\hline Pegfilgrastim and tripegfilgrastim & $63(3.0 \%)$ \\
\hline \multicolumn{2}{|l|}{ G-CSF for febrile neuropenia } \\
\hline Filgrastim & $470(22.7 \%)$ \\
\hline Lenograstim & $0(0 \%)$ \\
\hline
\end{tabular}

Table 1. Baseline characteristics of total study population.

\section{Methods}

Study population and design. We retrospectively reviewed the medical records of breast cancer patients who received PEGylated filgrastim during adjuvant or neoadjuvant chemotherapy from March 2015 to February 2020. In study population, two kinds of PEGylated filgrastim were used, which were pegfilgrastim (Neulasta-prefilled syringe $6 \mathrm{mg}$, Kyowa Hakko Kirin Co. Ltd) and tripegfilgrastim (Dulastin-prefilled syringe $6 \mathrm{mg}$, Dong-A ST Co. Ltd). The following baseline clinical data for PEGylated filgrastim-induced aortitis patients were collected: age, gender, comorbidity, chemotherapy regimen, G-CSF type, frequency of pegfilgrastim and other G-CSF administration before aortitis. Symptoms, time to onset, and extent of disease confirmed by computed tomography (CT) scans were retrieved as clinical manifestations. Laboratory tests including white blood cell counts, erythrocyte sedimentation rate (ESR), high-sensitivity C-reactive protein (CRP), procalcitonin, immunoglobulin, blood culture, and serologic markers of atypical pathogens and rheumatologic diseases were also conducted. This study was conducted in accordance with the Declaration of Helsinki and approved by the local institutional review board of Samsung Medical Center. (IRB File No. 2019-10-095-001) All of the methods were carried out in accordance with the approved guidelines and relevant regulations. Informed consent was waived for this retrospective study.

Diagnosis of acute aortitis. Based on clinical presentation including fever, myalgia, or chest/back pain without other infectious causes, CT scan of the entire aorta was performed with contrast enhancement. On CT scan, acute aortitis was defined by aortic inflammation as well as newly-developed enhancing aortic wall thickening with peri-aortic infiltration. To exclude other causes of aortitis, blood culture and serologic tests for atypical pathogens, autoimmune diseases or connective tissue diseases were also reviewed. The history of other treatment regimens, especially chemotherapy, was reviewed to exclude other drug-induced aortitis.

Statistical analysis. Baseline characteristics were described as numbers and percentages for all breast cancer patients treated with neoadjuvant or adjuvant chemotherapy. Continuous variables were presented as medians, standard deviation. Categorical variables were presented as percentages. All statistical analyses were performed using SPSS Statistics 23.0 (SPSS, Chicago, IL, USA).

\section{Results}

Baseline characteristics. A total of 2068 patients who underwent neoadjuvant/adjuvant chemotherapy with PEGylated filgrastim for breast cancer were consecutively enrolled in this study. Among study population, 1438 patients $(69.5 \%)$ received pegfilgrastim, 567 patients $(27.4 \%)$ received tripegfilgrastim, which is a biosimilar of pegfilgrastim, and 63 patients $(3.0 \%)$ had the history of both pegfilgrastim and tripegfilgrastim administration. Mean age of study populations was 49.9 years and 2065 patients $(99.9 \%)$ were female. In the study population, 470 patients $(22.7 \%)$ had a history of treatment with filgrastim due to febrile neutropenia. No lenograstim treatment history was found in the study population. These results are shown in Table 1. 
Clinical manifestations. Among 2068 consecutive patients who were treated with PEGylated filgrastim once or more, six patients $(0.3 \%)$ developed acute non-infectious aortitis. The median age of patients diagnosed with acute aortitis was 51.7 years. Two patients (Cases \#1 and \#2) developed aortitis during neoadjuvant chemotherapy, which was consist of docetaxel and carboplatin. And four patients (Cases \#3-6) had aortitis during adjuvant chemotherapy. In past medical history, there was no specific features related with giant cell arteritis or Takayasu arteritis. Acute symptoms related to aortitis including extremely high fever, chest/back pain and severe myalgia occurred 13.4 \pm 7.6 days after administration of pegfilgrastim. While three patients (Cases \#3, \#4 and \#6) developed aortitis when the the first dose of PEGylated filgrastim was conducted, other patients (Cases \#1, \#2 and \#5) developed aortitis after more than three times of PEGylated filgrastim injection. Except one patient (Case \#1) who had filgrastim instead of PEGylated filgrastim after experience of aortitis, G-CSF was no longer administered for other patients. In that patient who had filgrastim injection, instead of pegfilgrastim afterwards, aortitis was recurred with symptoms similar to the first episode. And inflammatory change of the aorta was observed in the same location with the first episode.

Laboratory and CT findings. In all patients, high fever (more than $39^{\circ} \mathrm{C}$ ) and high levels of CRP $(24.1 \pm 7.7 \mathrm{mg} / \mathrm{dL})$ were identified without any infection-related signs. To evaluate infectious aortitis, blood and urine culture were done and assays for Bartonella $\mathrm{Ab}$, Brucella $\mathrm{Ab}$, and $\mathrm{Q}$ fever antibody were conducted to distinguish atypical pathogens. Diagnostic tests for fluorescent antinuclear antibody, antineutrophil cytoplasmic antibody, rheumatoid factor and serum levels of immunoglobulin G4 (IgG4) subclass were also conducted for rheumatologic diseases, such as polyangiitis with granulomatosis or IgG4-related diseases. All serologic tests and cultures for infection or rheumatologic disease were negative in all cases.

The contrast-enhanced CT revealed enhanced segmental wall thickening of aorta with varying degrees of peri-aortic infiltration in all patients. These findings were consistently seen in the aortic arch (Fig. 1) and occasionally extended to branch arteries (Case \#3-6, Fig. 2). Peri-aortic infiltration was extended to thoracoabdominal junction of the aorta in two patients (Case \#1 and \#2). One patient (Case \#3) underwent positron-emission tomography-CT (PET-CT), which showed an increased FDG uptake (SUVmax =3.2) along the wall of aortic arch confirming acute vasculitis (see Supplementary Fig. S1 online).

Treatment of acute aortitis. Treatment with pegfilgrastim was discontinued, and prednisolone $0.5 \mathrm{mg} /$ $\mathrm{kg}$ /day was initiated. Initial symtoms and inflammatory markers were rapidly resolved within one week. After confirming the negative test results of infection and rheumatologic diseases, patients were discharged. Steroid treatment was tappered over 1-2 months. In one patient (Case \#1) who recurred aortitis after injection of filgrastim, warranted additional steroid therapy for 2 weeks. No further G-CSF treatment was administered in all patients during the remainder of chemotherapy. No significant post-aortitis complications or delay of scheduled chemotherapy were observed. The follow-up CT scans after more than 1 month from onset revealed a remarkable improvement in wall thickening and infiltration. Detailed clinical features and the result of treatment are depicted in Table 2 and Fig. 3.

\section{Discussion}

Drug-induced acute aortitis is extremely rare, but is a critical co-morbidity, especially in cancer patients requiring continuous chemotherapy. Here, we reported the incidence and clinical manifestations of PEGylated filgrastiminduced acute aortitis in breast cancer patients who underwent chemotherapy. Among the 2068 patients who received PEGylated filgrastim for prophylaxis of neutropenia, six patients developed acute aortitis (0.3\%). Common clinical presentations included extremely high fever and chest/back pain with high levels of CRP without any signs of infection. The onset of aortitis usually occurred within 2 weeks after PEGylated filgrastim injection. The contrast-enhanced CT scans revealed aortic enhancing wall thickening and peri-aortic soft tissue infiltration at various levels of aorta, most commonly along the aortic arch. All patients rapidly improved after administration of a modest dose of prednisolone without any complications and returned to chemotherapy as scheduled. To the best of our knowledge, this is the first study to report detailed clinical features of PEGylated filgrastim-induced acute aortitis during chemotherapy in patients with breast cancer.

In breast cancer patients, dose-dense chemotherapy involving administration of chemotherapy agents more frequently than typical chemotherapy, resulted in a significant improvement of clinical outcomes ${ }^{21,22}$. However, this intensified chemotherapy induces additional neutropenia and infection-related complications ${ }^{23}$. To prevent chemotherapy-induced febrile neutropenia, G-CSF was added to chemotherapy regimen and chemotherapy with PEGylated filgrastim yielded favorable clinical outcomes in breast cancer patient $\mathrm{s}^{24,25}$. Therefore, considering the fact that most of the breast cancer patients undergoes chemotherapy with PEGylated filgrastim, aortitis could occur more easily in breast cancer patients. However, for breast cancer, few data pertained to G-CSF-related aortitis including several case reports ${ }^{6,8-15,17-19}$ and two study from Adverse Drug Reporting (ADR) systems ${ }^{16,20}$. Data from the United States Food and Drug Administration Adverse Event Reporting System (FAERS) reported that the frequency of G-CSF-related aortitis was $0.0014 \%{ }^{20}$. Another data based on the Japanese ADR database reported the incidence of G-CSF-induced aortitis as $0.47 \%{ }^{20}$. Although those two results showed the association between G-CSF injection and the development of aortitis, they included the patients with malignancy and not exposed to chemotherapy with G-CSF in study population and did not report the detailed clinical courses including treatment of aortitis. Considering that chemotherapy with PEGylated filgrastim is widely used to treat breast cancer patients, one of the strengths of our study relates to the real-world incidence in consecutive patients and a comprehensive description regarding the clinical course of PEGylated filgrastim-induced aortitis in patients with breast cancer. 


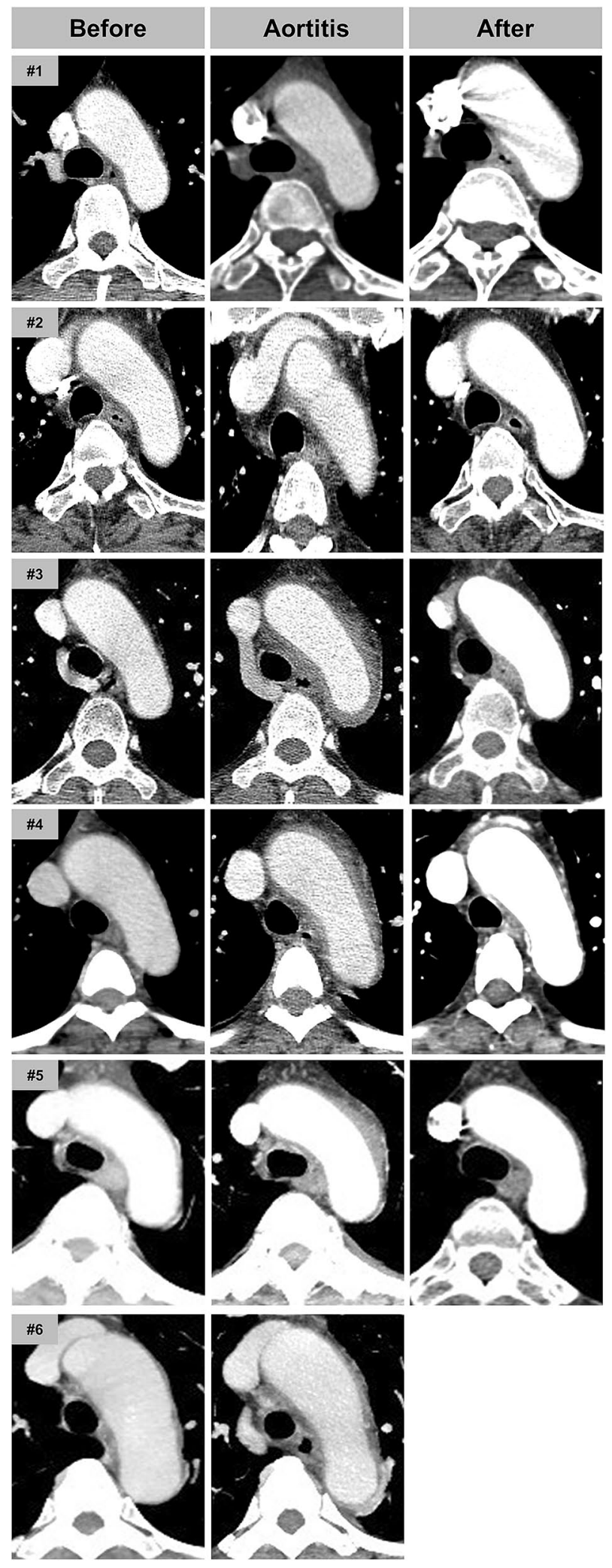

Figure 1. Serial CT images of aortic arch before, during and after PEGylated filgrastim-induced aortitis. Irregular wall thickening with periaortic infiltration is commonly observed in the aortic arch (Case \#1-\#6). After steroid treament, inflammatory changes of aortic wall were significantly improved. 

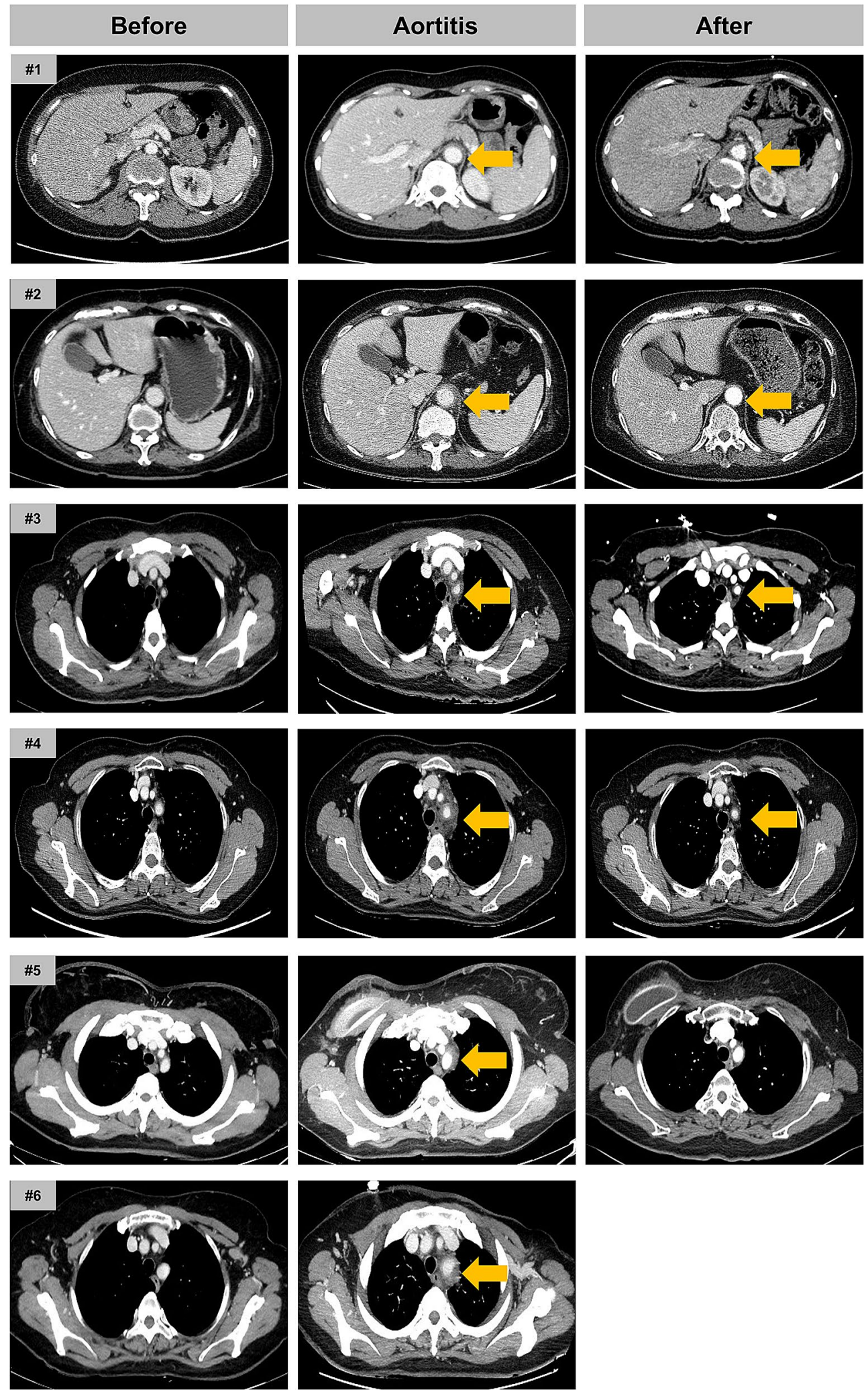

Figure 2. Various level of the aorta involvement in PEGylated filgrastim-induced aortitis. Case \#1 and Case\#2: abdominal aorta was involved. Case \#3-\#6: branching arteries from the aortic arch were involved. 


\begin{tabular}{|c|c|c|c|c|c|c|}
\hline & Case 1 & Case 2 & Case 3 & Case 4 & Case 5 & Case 6 \\
\hline \multicolumn{7}{|l|}{ Baseline characteristics } \\
\hline Age & 45 years & 66 years & 49 years & 50 years & 59 years & 53 years \\
\hline Gender & Female & Female & Female & Female & Female & Female \\
\hline Race & Asian & Asian & Asian & Asian & Asian & Asian \\
\hline Comorbidity & None & $\begin{array}{l}\text { Hypertension } \\
\text { Hypothyroidism }\end{array}$ & Hypertension & None & None & None \\
\hline $\begin{array}{l}\text { Chemotherapy indica- } \\
\text { tion }\end{array}$ & Neoadjuvant & Neoadjuvant & Adjuvant & Adjuvant & Adjuvant & Adjuvant \\
\hline Chemotherapy regimen & $\begin{array}{l}\text { Docetaxel } \\
\text { Carboplatin }\end{array}$ & $\begin{array}{l}\text { Docetaxel } \\
\text { Carboplatin }\end{array}$ & $\begin{array}{l}\text { Docetaxel } \\
\text { Cyclophosphamide }\end{array}$ & $\begin{array}{l}\text { Docetaxel } \\
\text { Cyclophosphamide }\end{array}$ & \begin{tabular}{|l|} 
Docetaxel \\
Carboplatin \\
Trastuzumab \\
Hertuzumab \\
\end{tabular} & $\begin{array}{l}\text { Docetaxel } \\
\text { Cyclophosphamide }\end{array}$ \\
\hline $\begin{array}{l}\text { G-CSF type at the onset } \\
\text { of aortitis }\end{array}$ & \begin{tabular}{|l|} 
Pegfilgrastim \\
Filgrastim(Recurrence)
\end{tabular} & Pegfilgrastim & Pegfilgrastim & Pegfilgrastim & Pegfilgrastim & Pegfilgrastim \\
\hline $\begin{array}{l}\text { Frequency of pegfil- } \\
\text { grastim before aortitis }\end{array}$ & 5 & 3 & 1 & 1 & 1 & 4 \\
\hline \multicolumn{7}{|l|}{ Clinical manifestations } \\
\hline Symptoms & \begin{tabular}{|l|} 
Fever \\
Myalgia \\
Chilling \\
Epigastric discomfort
\end{tabular} & \begin{tabular}{|l|} 
Fever \\
Chilling \\
Myalgia \\
Nausea \\
\end{tabular} & \begin{tabular}{|l|} 
Fever \\
Chest discomfort \\
Dyspepsia \\
Myalgia \\
\end{tabular} & $\begin{array}{l}\text { Fever } \\
\text { Chilling } \\
\text { Myalgia }\end{array}$ & $\begin{array}{l}\text { Fever } \\
\text { Myalgia } \\
\text { Chilling }\end{array}$ & $\begin{array}{l}\text { Fever } \\
\text { Chilling } \\
\text { Myalgia } \\
\text { Headache }\end{array}$ \\
\hline Physical examination & Abdominal tenderness & Abdominal tenderness & Unremarkable & Unremarkable & Unremarkable & Unremarkable \\
\hline Time to onset & $\begin{array}{l}\text { (1st) } 12 \text { days } \\
\text { (2nd) } 10 \text { days }\end{array}$ & 13 days & 15 days & 12 days & 17 days & 14 days \\
\hline Extent of disease & $\begin{array}{l}\text { Aortic arch } \\
\text { Abdominal aorta }\end{array}$ & $\begin{array}{l}\text { Aortic arch } \\
\text { Left CCA } \\
\text { Right innominate artery } \\
\text { Thoracic aorta } \\
\text { Abdominal aorta }\end{array}$ & $\begin{array}{l}\text { Aortic arch } \\
\text { Left CCA }\end{array}$ & $\begin{array}{l}\text { Aortic arch } \\
\text { Right innominate artery } \\
\text { Left SCA } \\
\text { Left CCA }\end{array}$ & $\begin{array}{l}\text { Aortic arch } \\
\text { Left CCA } \\
\text { Right innominate artery } \\
\text { Thoracic aorta } \\
\text { Abdominal aorta }\end{array}$ & $\begin{array}{l}\text { Aortic arch } \\
\text { Left CCA }\end{array}$ \\
\hline \multicolumn{7}{|l|}{ Laboratory findings } \\
\hline WBC count, $\times 10^{3} / \mu \mathrm{L}$ & $\begin{array}{l}7.46 \\
\text { (Neutrophil-dominant) }\end{array}$ & \begin{tabular}{|l|l|}
19.76 \\
(Neutrophil-dominant)
\end{tabular} & \begin{tabular}{|l|}
12.33 \\
(Neutrophil-dominant)
\end{tabular} & \begin{tabular}{|l|}
38.29 \\
(Neutrophil-dominant)
\end{tabular} & $\begin{array}{l}16.91 \\
\text { (Neutrophil-dominant) }\end{array}$ & $\begin{array}{l}11.25 \\
\text { (Neutrophil-dominant) }\end{array}$ \\
\hline ESR, $\mathrm{mm} / \mathrm{h}$ & 53 & 118 & 119 & 69 & 120 & 64 \\
\hline $\mathrm{CRP}, \mathrm{mg} / \mathrm{dL}$ & 23.11 & 26.63 & 21.76 & 29.58 & 32.86 & 10.85 \\
\hline Procalcitonin, ng/mL & 0.04 & 0.26 & 0.18 & 0.05 & 0.28 & 0.04 \\
\hline Blood culture & Negative & Negative & Negative & Negative & Negative & Negative \\
\hline Infection serology ${ }^{a}$ & Negative & Negative & Negative & Negative & Negative & Negative \\
\hline Rheumatologic markers & $\begin{array}{l}\text { RF/FANA/ANCA } \\
(-/-l-)\end{array}$ & $\begin{array}{l}\text { RF/FANA/ANCA } \\
(-/-l-)\end{array}$ & $\begin{array}{l}\text { RF/FANA/ANCA } \\
(-I-I-)\end{array}$ & $\begin{array}{l}\text { RF/FANA/ANCA } \\
(-/-l-)\end{array}$ & $\begin{array}{l}\text { RF/FANA/ANCA } \\
(-/-I-)\end{array}$ & No data \\
\hline Immunoglobulin (IgG4) & No data & No data & Normal & Normal & Negative & No data \\
\hline
\end{tabular}

Table 2. PEGylated filgrastim-induced aortitis among breast cancer patients treated with neoadjuvant or adjuvant chemotherapy. CCA common carotid artery, SCA subclavian artery. ${ }^{\text {anfectious markers including }}$ following tests: syphilis, Salmonella, Borrelia, Mycoplasma, Chlamydia, Richettsia, Q fever, Brunella, Bartonella, Legionella, M. tuberculosis.

G-CSF stimulates proliferation and diffrentiation of neutriphil precursors, enhances chemotaxis and mobilizes hematopoietic stem cells ${ }^{26}$. Aortitis might be triggered via increased pro-inflammatory reaction and neutrophilmediated damage ${ }^{27}$. Additionally, G-CSF-induced autoimmune reactions mediated via IL- 6 between Th17 cells and CD4+ T cells is also thought to result in aortitis, aneurysm or dissection ${ }^{9,10,28}$. In fact, blood tests at the onset of PEGylated induced-aortitis patients showed a significant increase in G-CSF as well as neutrophil and cytokine levels ${ }^{10}$. Based on this immune-related vascular inflammation as one of the main mechanisms underlying the development of aortitis, all our patients were treated with short-term steroids to induce immunosuppression. While some data showed spontaneous improvement of aortitis without anti-inflammatory agents ${ }^{8,11}$, we thought that the recovery without anti-inflammatory agents might take longer than for the use of glucocorticoid, and delay recovery could directly affect the anticancer treatment schedule. Anticipating no further delay in chemotherapy, it may be reasonable to consider short-term glucocorticoid treatment. Further studies are warranted to determine the appropriate duration of steroid administration and indications for the restart of chemotherapy.

Early diagnosis of G-CSF-induced aortitis can be established based on high fever and chest/back pain combined with remarkable elevation in inflammatory markers, when G-CSF administration is known. Despite the high levels of CRP and ESR, these patients appear to be stable without symptoms related to infection or autoimmune disease. There have been a difference of the time from G-CSF administration to the onset of aortitis among the studies. It might vary depending on how aortitis-indicating symptoms were defined. Because mild fever and general ache are frequently observed in cancer patients after chemotherapy regardless of G-CSF administration, we defined aortitis-indicating symptoms as extremely high fever and localizing chest/back pain without other infection-related signs. Therefore, the symptom onset time was longer than the previous data ${ }^{17}$. Immediate chest 
Day 0 : PEGylated Filgrastim (Case \#1-4)

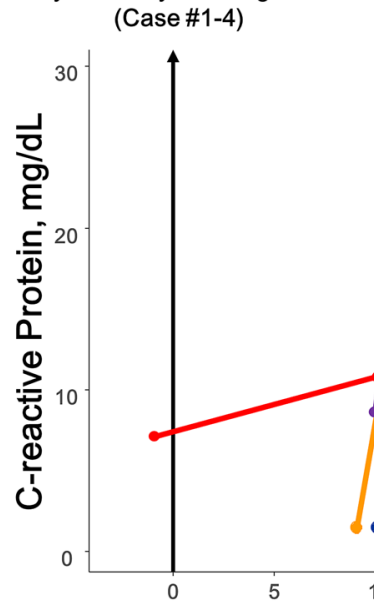

Day 0 : PEGylated Filgrastim

$$
\text { (Case \#1-4) }
$$

ป

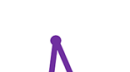

Day 42 : Filgrastim for 5 days

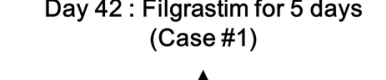

Day 42 : Filgrastim for 5 days
(Case \#1)

10

\begin{tabular}{c|cccc}
15 & 20 & 25 & 30 & 35
\end{tabular}

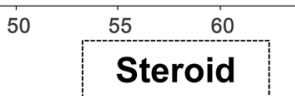

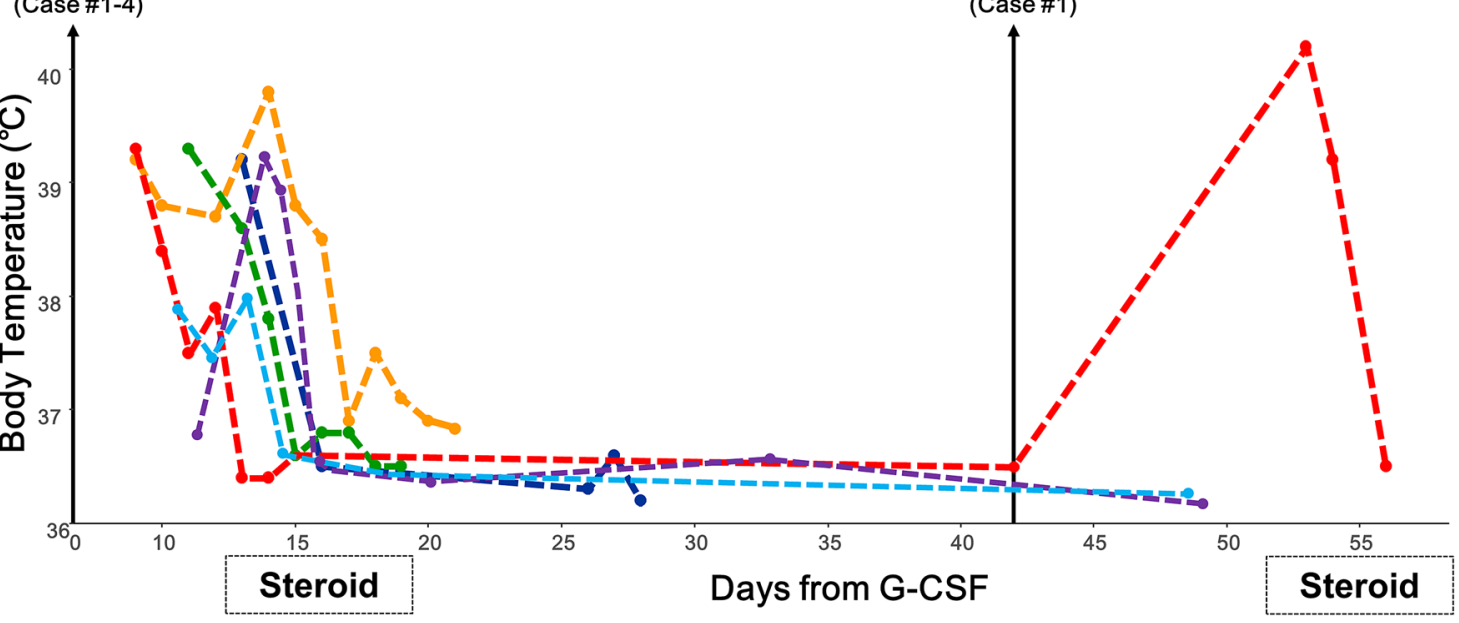

- Case \#1

- Case \#2

- Case \#3

-. Case \#4

- - Case \#5

- Case \#6

Figure 3. Clinical course of PEGylated filgrastim-induced aortitis. C-reactive protein (CRP) and body temperature during the clinical course of PEGylated filgrastim-induced aortitis. CRP level and fever rapidly improved after steroid administration in cases \#1, \#4, \#5 and \#6. In cases \#2 and \#3, CRP and fever already improved at the time of steroid administration.

CT or CT aortography is indicated considering the risk of disease spread to proximal aorta, such as aortic arch or ascending thoracic aorta. Of course, even if G-CSF induced aortitis is suspected, the tests for infection and rheumatic disease are required at the same time. Procalcitonin, which is associated with the extent and severity of bacterial infection ${ }^{29}$, was within normal range despite the highly elevated ESR/CRP. This finding may facilitate to exclude the diagnosis of other suspected causes of fever and inflammation.

A comprehensive review of past medications for the patients with aortitis are also important. Few case reports showed the aortitis caused by gemcitabine or bevacizumab ${ }^{30-32}$. Similary with the preivous data ${ }^{8,11-13,17-19}$, docetaxel was concorrently used in our aortitis patients. However, aortitis did not recur during the remainder of docetaxel chemotherapy without G-CSF after aortitis. Therefore, we thought docetaxel was not the primary cause of aortitis. Some data have suggested there might be a potential interaction between taxanes and G-CSF, and their synergistic effect might promote vasculitis ${ }^{17,33}$.

Compared with the other cases discontinuing G-CSF treatment, Case \#1 was exposed to filgrastim instead of pegfilgrastim after the resolution of the initial aortitis-related symptoms. Except our data (Case \#1), no report of recurrent aortitis after administration of another type of G-CSF has been reported. Clinicians should be cautious when re-administration of G-CSF, even if it is a different type of G-CSF with the prior agent, considering the possibility of cross-reaction between drugs. Notably, in the present study, all cases of aortitis were induced by pegfilgrastim, which is an original PEGylated filgrastim made by Kyowa Hakko Kirin Co. Ltd. Among patients who received tripegfilgrastim, which is a biosimilar of pegfilgrastim, no aortitis occurred. According to previous studies including data from Japan ADR database ${ }^{6,8-20}$, the biosimilars of G-CSF did not cause aortitis. Taken together, although the mechanism is unknown, biosimilars of G-CSF can be the alternatives when G-CSF administration is inevitable for patients. 
According to the previous studies to date, the incidence of G-CSF induced aortitis is higher in East Asian. Pegfilgrastim is world widely used G-CSF, so the difference in the incidence of G-CSF induced aortitis might not be due to the difference in the rate of drug use. One of the possible explanation is that a certain genetic predisposition might be related to the increased incidence of G-CSF induced aortitis in Asian. Th17 cell pathway, which is considered as one of the pathogenesis of G-CSF induced aortitis, is also known to contribute to the systemic and vascular manifestations of Takayasu's arteritis that is common in East Asia ${ }^{10,34}$. Genetic susceptibility to large vessel inflammatory change might have caused differences in the frequency of drug-related vasculitis between races. Underdiagnosis should be considered as another explanation for relatively low incidence of G-CSF induced aortitis in Western. In terms of G-CSF induced aortitis, it is difficult to diagnose without clinical suspicion and early imaging evaluation. Future large scale studies are warranted to identify the exact incidence of G-CSF induced aortitis and bring awareness to physicians.

The present study had several limitations. First, this was a single center retrospective study. Second, the number of patients was relatively small; however, all patients were enrolled consecutively and our study focused on discrete manifestations of aortitis. Lastly, among patients who presented with fever, chest/back pain and elevated inflammatory markers, patients were diagnosed with pegfilgrastim-related aortitis only when the newly developed aortic wall thickening was detected in imaging tests, the temporal relationship was evident following pegfilgrastim injection, and the exclusion of infection and autoimmune disease was established. Because of the strict diagnositc criteria for aortitis, the exact incidence might be underestimated.

In conclusion, among breast cancer patients who were treated with adjuvant/neoadjuvant chemotherapy including PEGylated filgrastim, the incidence of PEGylated filgrastim-induced acute aortitis was $0.3 \%$. Although not established as a treatment of choice, short-term steroid administration and avoidance of all G-CSF types can be effective in these patients. In view of the remarkable systemic symptoms associated with aortitis, which can be misdiagnosed as infection in neutropenic patients undergoing chemotherapy, clinicians should be aware of aortitis as a possible complication of G-CSF therapy, especially in breast cancer patients treated with PEGylated filgrastim.

Received: 16 April 2020; Accepted: 16 October 2020

Published online: 29 October 2020

\section{References}

1. Gornik, H. L. \& Creager, M. A. Aortitis. Circulation 117, 3039-3051. https://doi.org/10.1161/circulationaha.107.760686 (2008).

2. Bossone, E. et al. Aortitis. Vascul. Pharmacol. 80, 1-10. https://doi.org/10.1016/j.vph.2015.11.084 (2016).

3. Smith, T. J. et al. Recommendations for the use of WBC growth factors: American Society of Clinical Oncology Clinical Practice Guideline Update. J. Clin. Oncol. 33, 3199-3212. https://doi.org/10.1200/JCO.2015.62.3488 (2015).

4. Conti, J. A. \& Scher, H. I. Acute arterial thrombosis after escalated-dose methotrexate, vinblastine, doxorubicin, and cisplatin chemotherapy with recombinant granulocyte colony-stimulating factor: a possible new recombinant granulocyte colony-stimulating factor toxicity. Cancer 70, 2699-2702 (1992).

5. Kawachi, Y. et al. Acute arterial thrombosis due to platelet aggregation in a patient receiving granulocyte colony-stimulating factor. Br. J. Haematol. 94, 413-416 (1996).

6. Darie, C. et al. Aortite après injections de G-CSF. La Revue de Médecine Interne 25, 225-229. https://doi.org/10.1016/j.revme d.2003.10.015 (2004).

7. Molineux, G. et al. A new form of filgrastim with sustained duration in vivo and enhanced ability to mobilize PBPC in both mice and humans. Exp. Hematol. 27, 1724-1734 (1999).

8. Adiga, G. U., Elkadi, D., Malik, S. K., Fitzpatrick, J. D. \& Madajewicz, S. Abdominal aortitis after use of granulocyte colonystimulating factor. Clin. Drug Investig. 29, 821-825. https://doi.org/10.2165/11530790-000000000-00000 (2009).

9. Miller, E. B., Grosu, R. \& Landau, Z. Isolated abdominal aortitis following administration of granulocyte colony stimulating factor (G-CSF). Clin. Rheumatol. 35, 1655-1657. https://doi.org/10.1007/s10067-016-3253-6 (2016).

10. Sato, Y., Kaji, S., Ueda, H. \& Tomii, K. Thoracic aortitis and aortic dissection following pegfilgrastim administration. Eur. J. Cardiothorac. Surg. 52, 993-994. https://doi.org/10.1093/ejcts/ezx165 (2017).

11. Kinjo, Y. et al. Acute arteritis after G-CSF administration. Int. Cancer Conf. J. 8, 77-80. https://doi.org/10.1007/s13691-018-00357 $-z(2019)$.

12. Mukai, T., Kubo, S., Morita, Y., Yamamoto, M. \& Ikeda, M. Aortitis which developed after the administration of granulocyte-colony stimulating factor. Mod. Rheumatol. Case Rep. https://doi.org/10.1080/24725625.2019.1629570 (2019).

13. Parodis, I. et al. G-CSF-induced aortitis: two cases and review of the literature. Autoimmun. Rev. 18, 615-620. https://doi. org/10.1016/j.autrev.2018.12.011 (2019).

14. Sasaki, K. et al. Arteritis after administration of granulocyte colony-stimulating factor: a case series. Int. J. Hematol. 110, 370-374. https://doi.org/10.1007/s12185-019-02662-6 (2019).

15. Yukawa, K., Mokuda, S., Yoshida, Y., Hirata, S. \& Sugiyama, E. Large-vessel vasculitis associated with PEGylated granulocyte-colony stimulating factor. Neth. J. Med. 77, 224-226 (2019).

16. Lardieri, A., McCulley, L., Christopher Jones, S. \& Woronow, D. Granulocyte colony-stimulating factors and aortitis: a rare adverse event. Am. J. Hematol. 93, E333-E336. https://doi.org/10.1002/ajh.25220 (2018).

17. Taimen, K. et al. Granulocyte colony-stimulating factor- and chemotherapy-induced large-vessel vasculitis: six patient cases and a systematic literature review. Rheumatol. Adv. Pract. 4, rkaa004. https://doi.org/10.1093/rap/rkaa004 (2020).

18. Chino, T. et al. A case of arteritis that developed after pegfilgrastim administration during chemotherapy for breast cancer. Gan to Kagaku ryoho Cancer Chemother. 45, 1771-1774 (2018).

19. Hoshina, H. \& Takei, H. Granulocyte-colony stimulating factor-associated aortitis in a woman with advanced breast cancer: a case report and review of the literature. BMC Cancer 19, 1217. https://doi.org/10.1186/s12885-019-6403-9 (2019).

20. Oshima, Y., Takahashi, S., Tani, K. \& Tojo, A. Granulocyte colony-stimulating factor-associated aortitis in the Japanese adverse drug event report database. Cytokine 119, 47-51. https://doi.org/10.1016/j.cyto.2019.02.013 (2019).

21. Citron, M. L. et al. Randomized trial of dose-dense versus conventionally scheduled and sequential versus concurrent combination chemotherapy as postoperative adjuvant treatment of node-positive primary breast cancer: first report of intergroup trial C9741/ cancer and leukemia group B trial 9741. J. Clin. Oncol. 21, 1431-1439. https://doi.org/10.1200/jco.2003.09.081 (2003).

22. Kummel, S. et al. Randomised trial: survival benefit and safety of adjuvant dose-dense chemotherapy for node-positive breast cancer. Br. J. Cancer 94, 1237-1244. https://doi.org/10.1038/sj.bjc.6603085 (2006). 
23. Aapro, M. S. et al. EORTC guidelines for the use of granulocyte-colony stimulating factor to reduce the incidence of chemotherapy-induced febrile neutropenia in adult patients with lymphomas and solid tumours. Eur. J. Cancer 42, 2433-2453. https://doi. org/10.1016/j.ejca.2006.05.002 (2006).

24. Vogel, C. L. et al. First and subsequent cycle use of pegfilgrastim prevents febrile neutropenia in patients with breast cancer: a multicenter, double-blind, placebo-controlled phase III study. J. Clin. Oncol. 23, 1178-1184. https://doi.org/10.1200/JCO.2005.09.102 (2005).

25. Holmes, F. A. et al. Blinded, randomized, multicenter study to evaluate single administration pegfilgrastim once per cycle versus daily filgrastim as an adjunct to chemotherapy in patients with high-risk stage II or stage III/IV breast cancer. J. Clin. Oncol. 20, 727-731 (2002).

26. Semerad, C. L., Liu, F., Gregory, A. D., Stumpf, K. \& Link, D. C. G-CSF is an essential regulator of neutrophil trafficking from the bone marrow to the blood. Immunity 17, 413-423 (2002).

27. Cuchacovich, R. Immunopathogenesis of vasculitis. Curr. Rheumatol. Rep. 4, 9-17 (2002).

28. Anzai, A. et al. Adventitial CXCL1/G-CSF expression in response to acute aortic dissection triggers local neutrophil recruitment and activation leading to aortic rupture. Circ. Res. 116, 612-623. https://doi.org/10.1161/circresaha.116.304918 (2015).

29. Schuetz, P., Albrich, W. \& Mueller, B. Procalcitonin for diagnosis of infection and guide to antibiotic decisions: past, present and future. BMC Med. 9, 107 (2011).

30. Hiranuma, K. et al. Drug-induced aortitis in a patient with ovarian cancer treated with bevacizumab combination therapy. Taiwan J. Obstet. Gynecol. 57, 750-752. https://doi.org/10.1016/j.tjog.2018.08.026 (2018).

31. Eyre, T. A. et al. Gemcitabine-induced large vessel vasculitis demonstrated by PET CT: a rare, important side effect. Int. J. Hematol. 99, 798-800. https://doi.org/10.1007/s12185-014-1555-5 (2014).

32. Ramsay, L. B. et al. Gemcitabine-associated large vessel vasculitis presenting as fever of unknown origin. JCR J. Clin. Rheumatol. 16, 181-182. https://doi.org/10.1097/RHU.0b013e3181df91ad (2010).

33. Omidvari, S. et al. Drug-induced vasculitis in a breast cancer patient receiving chemotherapy. Rep. Radiother. Oncol. 1, 81-84 (2013).

34. Saadoun, D. et al. Th1 and Th17 cytokines drive inflammation in Takayasu arteritis. Arthritis Rheumatol. 67, 1353-1360. https:// doi.org/10.1002/art.39037 (2015)

\section{Author contributions}

L.S.Y., K.E.K., P.Y.H. and K.D.K. conceived the study. L.S.Y., K.J.Y., I.Y.H., P.T.K. and C.S.H. collected the data and perfored the statistical analysis. L.S.Y., K.E.K., K.M.Y. and K.J.Y. reviewed the data and wrote the main manuscript.

\section{Competing interests}

The authors declare no competing interests.

Additional information

Supplementary information is available for this paper at https://doi.org/10.1038/s41598-020-75620-6.

Correspondence and requests for materials should be addressed to E.K.K.

Reprints and permissions information is available at www.nature.com/reprints.

Publisher's note Springer Nature remains neutral with regard to jurisdictional claims in published maps and institutional affiliations.

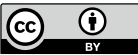

Open Access This article is licensed under a Creative Commons Attribution 4.0 International License, which permits use, sharing, adaptation, distribution and reproduction in any medium or format, as long as you give appropriate credit to the original author(s) and the source, provide a link to the Creative Commons licence, and indicate if changes were made. The images or other third party material in this article are included in the article's Creative Commons licence, unless indicated otherwise in a credit line to the material. If material is not included in the article's Creative Commons licence and your intended use is not permitted by statutory regulation or exceeds the permitted use, you will need to obtain permission directly from the copyright holder. To view a copy of this licence, visit http://creativecommons.org/licenses/by/4.0/.

(C) The Author(s) 2020 